Association for Information Systems

AIS Electronic Library (AISeL)

\title{
Playing (Government) Seriously: Design Principles for e- Government Simulation Game Platforms
}

\author{
Sebastian Halsbenning \\ University of Münster, ERCIS, Münster, Germany \\ Marco Niemann \\ University of Münster, ERCIS, Münster, Germany \\ Bettina Distel \\ University of Münster, ERCIS, Münster, Germany \\ Becker Jörg \\ University of Münster, ERCIS, Münster, Germany
}

Follow this and additional works at: https://aisel.aisnet.org/wi2021

Halsbenning, Sebastian; Niemann, Marco; Distel, Bettina; and Jörg, Becker, "Playing (Government) Seriously: Design Principles for e-Government Simulation Game Platforms" (2021). Wirtschaftsinformatik 2021 Proceedings. 2.

https://aisel.aisnet.org/wi2021/KDigitalEducation15/Track15/2

This material is brought to you by the Wirtschaftsinformatik at AIS Electronic Library (AISeL). It has been accepted for inclusion in Wirtschaftsinformatik 2021 Proceedings by an authorized administrator of AIS Electronic Library (AISeL). For more information, please contact elibrary@aisnet.org. 


\title{
Playing (Government) Seriously: Design Principles for e-Government Simulation Game Platforms
}

\author{
Sebastian Halsbenning ${ }^{1}$, Marco Niemann ${ }^{1}$, Bettina Distel ${ }^{1}$, and Jörg Becker ${ }^{1}$ \\ ${ }^{1}$ University of Münster, ERCIS, Münster, Germany \\ \{halsbenning, niemann, distel, becker\} @ercis. de
}

\begin{abstract}
The digital transformation of the public sector is progressing but regularly not at the desired pace. Here, the digitalization skills of public officials are one important resource to cope with the demanding digital shift and rise of egovernment. As there is still a lack of those competences, alternative educational approaches are needed. Promising and flexible methods are simulation gamesalthough not widely used in the public sector. As a resolve, we are developing on a corresponding simulation game platform for about two years. In addition to sharing the artifact, this manuscript shall provide a set of design principles helping to create and facilitate the adoption of related platforms for the public sector.
\end{abstract}

Keywords: simulation game platform, digitalization skills, e-government, design principles, competences

\section{Introduction}

Digitalization changes the service delivery and the internal organization of public administrations. In the public sector, this technological shift has become an important means to raise citizen-centricity and efficiency [1], for example, through digitalized services or reorganized workflows. Moreover, in research and practice, decent progress in technologies and concepts can be observed that take digital opportunities to enhance the performance of the public sector by, e.g., instantiating one-stop governments [2], offering proactive service delivery [3], or open-government initiatives [4]. The constantly increasing application and use of these new concepts and technological innovations are accompanied by a need for corresponding digitalization competences for public officials [5]. Those e-competences refer to one's ability to cope with digitalization and have to be constantly trained early on. Considering the strong influence of e-government on daily routines, adequate digitalization skills have become a success factor for e-government projects [6,7]. Although this need has already been specified, e-competences are still a bottleneck to the digitalization of the public sector. One crucial reason for the shortage of e-competences in the public sector can be rooted back to education. As the education of future public officials primarily concentrates on legal, economic, and management aspects, a lack of a broad institutional penetration of e-competence is the result. Consequently, there is a need to focus more on teaching the required competences and IT skills not only on the job but already in educational

16th International Conference on Wirtschaftsinformatik,

March 2021, Essen, Germany 
programs. This article addresses this gap in research and practice by focusing on the development of e-competences among public sector students.

As a solution for this problem, a growing number of recommendations of serious gaming or simulation games can be found in research [8,9] including application scenarios in the area of information systems [10] and e-government [11, 12]. Especially for university programs in the field of public sector, simulation games are a suitable means for getting the learners used to the complex mesh of stakeholders in the political and administrative environment. Therefore, simulation games for teaching egovernment settings have been established, the one by [12] being both comparatively recent and positively evaluated. We abstracted from the exact contents and setting of the presented game in order to create a simulation game platform (SGP) that is capable of hosting a series of structurally similar to equivalent setups. Looking at the overall lack of e-government competences in the public sector [13,14], as well as the many competence areas [15] and the diversity of public administrations, it appears to be mandatory to be able to provide - over time - a series of similar simulations to account for the different educational needs. Further need for flexibility regarding the exact setup arises from the educational setting of the game - to keep it interesting for multiple iterations of students, changes must be easily possible, as otherwise inter-student exchange will lead to boredom. Hence, we build upon this research to further develop the idea by addressing the following two research goals:

(1) Design and evaluation of a configurable platform for simulation games tailored to the public administration domain.

(2) Development of design principles for e-government SGPs.

Therefore, we use a classical design science approach to pursue our research goals. We combine our prior, initial research on a simulation game platform with the simulation game scenario by [12] to derive design principles for e-government SGPs. The paper is structured as follows. In section 2, we outline the background of our research on e-government competences and SGPs. Then, in sections 3 to 5, we explain the research design, the platform, and the setting in which our research has been conducted. This is followed by the presentation of our artifacts and the evaluation in section 6. The paper is closed by a discussion of our findings as well as extant implications for further research.

\section{Research Background}

\section{1 e-Competences and e-Government Simulation Games}

The use of information and communication technologies to deliver public services (egovernment) still concerns public administrations around the world. It is less the technical dimension that continues to challenge public organizations. Rather, practitioners and researchers alike point to the need of the workforce to adapt to and, eventually, design the digital transformation $[12,16]$. The pace these technologies evolve at creates a substantial challenge insofar as the public workforce has to adapt to the changes accordingly. Even more, formerly valuable competences tend to become less important or even obsolete, while completely new competences, such as digital literacy, programming skills, and data science knowledge, need to be acquired $[17,18]$. 
It is noteworthy that digital transformation not only requires the acquisition of technical competences. In contrast, researchers tend to identify more non-technical than technical competences as important such as business competences [18], project management competences [17], and socio-technical competences [15]. To ensure that future administrative staff is able to adapt quickly to changing conditions and to actively design the digital transformation, the necessary competences must be trained during their education.

The question remains how students can acquire these competences. Traditional programs and teaching formats need to be adapted with both new content (imparting new competences) and new learning strategies (imparting competences with new formats). Gamification and simulation games in particular have been proposed as one meaningful way to impart competences [19-21]. Simulation games not only train competences in a risk-free environment [12] but can also convey the complexities and oftentimes opaque structures in which public organizations act [11].

This article is based on a fairly recent simulation game in the domain of egovernment that aims at imparting non-technical competences for public sector students [12]. Through this game, students train "[...] competences that cannot be taught through rather classic formats of instruction, such as cooperation, strategy development, and decision making" [12:3089]. This simulation game evolves around the (so far) fictitious overall scenario of the nation-wide introduction of service accounts in Germany. It consists of sixteen different roles the students are assigned to. The roles cover functions in the public sector, such as state governments and municipal administrations, private sector companies and lobby groups, political parties, and public IT providers. Each role is assigned to one student and has a 'secret' goal concerning the introduction of service accounts. These goals are designed as conflicts among the players. For example, one party is designed as techno-averse and aims at impeding the digital transformation. One of the state governments, however, wants to become the digital frontrunner and pushes digital innovations such as service accounts. Throughout the game, five events happen that challenge each role and define the further course of the game (conference on digital transformation, data leakage at the federal level, the bankruptcy of a municipality, state elections and change in government, national digital summit). One of these events, for example, is a data leakage at the Federal Ministry of the Interior. Millions of data sets of both businesses and citizens are leaked and this data breach changes the public opinion on the introduction of service accounts. As an example of the effects on particular roles and the overall course of the game, consider the following situations: The techno-averse party profits from this opinion swing as it questions digitalization in general, whereas the digital-oriented roles in this game (states, municipalities, businesses) need to address the public's concerns regarding data security and face difficulties in justifying their techno-friendly policies. The overall support for the service accounts is eroded and all roles involved need to take measures either to use this situation for their benefit or to prevent further damage. In total, five of these events shape the course of the simulation game [cf. for further details 12].

The students have to participate both in formal meetings, such as a simulated press conference and the simulated digital summit, and more informal meetings such as backroom talks either presenting and debating their positions or discussing the course 
of action with potential allies. The formal meetings are mainly organized by the teachers who act, for example, as conference chairs. The informal meetings have to be organized by the students themselves and the teachers are involved only upon request, for example, as negotiators.

Initially, the game was designed in a hybrid format, i.e., with both analogue and digital elements. The meetings - both formal and informal - were held in person, whereas press releases or comments could be posted via the university's Moodle platform (first iteration) or the SGP (second iteration). Furthermore, the game management was done digitally, i.e., announcements on the events and individual tasks were released via the platforms. However, reacting to the COVID-19 pandemic, the third iteration of the simulation game was executed as an online-only format using the SGP to its full extent as meetings in presence were not possible. Using both analogue and digital elements for this simulation game aims at mimicking the hybrid nature of real-life situations. Thereby, the simulation game trains competences that are otherwise hard to acquire through traditional teaching formats: soft skills such as leadership or conflict management, socio-technical competences such as politics of e-government, organizational and managerial competences such as process and change management, and finally, political-administrative competences such as legal framework knowledge [12].

\subsection{Design of Simulation Game Platforms}

Beyond the scenario as the abstract setting of a simulation game, the medium for its execution can be seen as a second layer or perspective on a simulation game, also referred to as the game interface design [22]. While simulation gaming and gamification have grown to separate fields of research during the last decade [23, 24], a research focus has primarily been given to its educational impact and its contribution to the learning success $[25,26]$. In general, the results are oftentimes mixed and depend on the application context and circumstances of the simulation game under investigation [22, 27]. However, the learning outcomes of games applying (web-based) platforms are being positively evaluated [e.g., 28-31] but, here, the insights regarding platform design are limited to the individual implementation setting. Also, most of the related research does not divide the development process between the story and the implemented platform or piece of software.

Hence, research provides little guidance on the specifics of platform development or the choice of appropriate media for executing simulation games. This might be rooted back to the heterogeneity of simulation games, e.g., regarding applied game-design elements, degree and type of interaction among participants, and also the domain of application. Typically, the derivation of game-design elements is conducted independent of and prior to any platform development, as simulation games are also often used in offline or blended settings before being digitalized. They are subdivided into game mechanics and game dynamics, whereby game mechanics define the 'building blocks' of a game and game dynamics the consequential effects, e.g., competition, collaboration, and challenge [24]. Thus, the type of user interaction depends on both types of game-design elements but also the use of the general teaching setting, i.e., online, offline, or blended learning. In addition, for each domain of 
application different types of game-design elements might be preferable as this also depends on the learning objective [e.g., 27, 28, 32].

Table 1. Proposed design principles by [23:5-7]

1 Educational games must be purposefully built on game platforms that can adapt to various educational purposes.

2 Educational games must be purposefully built on game platforms that can scale to achieve the desired level of complexity.

3 Educational games platforms must be highly configurable to allow educators to design the workflow of the game relatively fast.

4 Educational platforms must allow educators to enable and disable features of personification (avatar), game rewards, student reputation/ranking.

5 Educational platforms must allow educators to create games at varying degrees of interaction between students (competitiveness, cooperation).

6 Educational platforms must allow educators to define the level of ludic loops (pleasurable feedback loops between the game and the student).

7 Educational platforms must keep students in a state of arousal by continuously maintaining the games' challenge levels one grain higher than the students' skill levels.

Given all these aspects that affect the digital representation of the game scenario, only a few attempts exist to translate these requirements into general design recommendations, i.e. reference models [33] or design principles [23]. The reference models for SGPs can be used as a starting point for conceptualizing a platform. As such reference models contain a strong processual view on the implementation of a serious game platform. In contrast, design principles extend design theory and aim at providing general design knowledge [34, 35]. By introducing (preliminary) design principles for SGPs, [23] address a research gap by providing a broad view on the needed actions for setting up an SGP (cf. Table 1). Their principles are designed to overcome the adoption barriers to using simulation games. However, the design principles are not yet evaluated or tested and lack positioning regarding application domains.

\section{Research Design}

Our research aims at both, the development of an innovative platform to host simulation games supporting competence education efforts in e-government as well as the derivation of design principles that can guide the development of similar platforms. Hence, we follow the Design Science paradigm as postulated by [36, 37]. Given our work on applicable (IT) artifacts our research can best be located in the genres design science research methodology (DSRM) and design-oriented IS research (DOIS) as presented by [38].

Hence, the design process follows the steps proposed by [37] (cf. Figure 1). First, an existing problem has been identified (the lack of e-competences in administrative personnel; cf. Section 1 and 2 and [12]). Subsequently, the first objectives were defined by [12] - primarily regarding the creation of simulation games to enhance ecompetences. It should be noted that the work of [12] in itself represents a full iteration through the DSR cycle depicted in Fig. 1. However, the artifact to be created was a different one, i.e., the simulation game as a concept, which was the conceptual baseline for the development of the configurable SGP. Hence, for this research, it is only linked as an informative publication to the first two phases. 


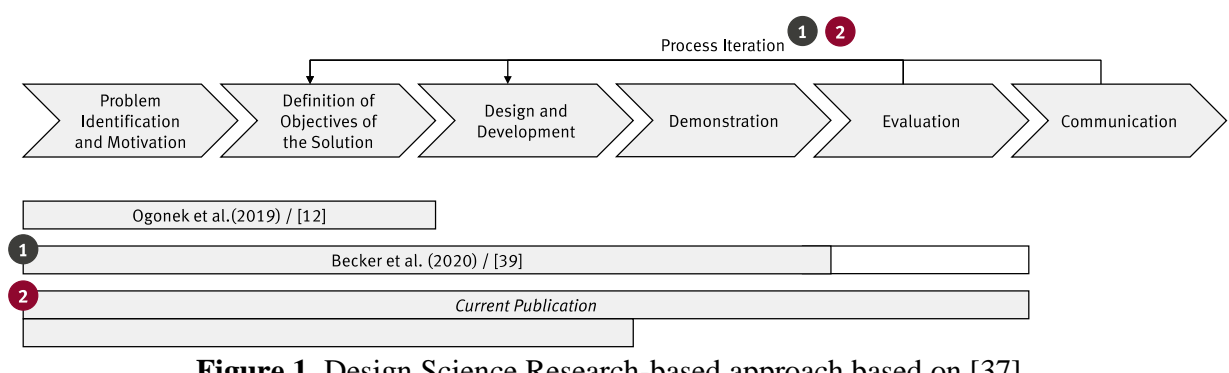

Figure 1. Design Science Research-based approach based on [37]

However, the game was taken as the initial template for designing the platform but a previous step for our endeavor was to make the game as such scalable. Therefore, we first transferred the whole game setting into a digital counterpart including the structure with 16 roles and five events. As student groups are of different size and we are consequently aiming at a configurable platform, we extended the set of game roles while keeping the overall simulation game story. For example, we added the roles Green and Sustainable or IT Planning Council that were similarly integrated into the overall scenario as the initial set of roles.

Beyond these conceptual objectives, [39] identified that teaching digital competences based on pen and paper is a problematic endeavor (back to Step 1 in Figure 1) - sketching first solution objectives for a digital SGP to support such competenceenhancing serious games. This contribution includes but is not limited to proposals for the enhanced execution or better support of remote teaching. Being a constructionoriented research approach [40], a first software artifact of the Game of Competences (GoC) was developed - which can be considered an "instantiation" artifact type [36] and a contribution of "Level 1" [41], respectively. The derived IT artifact was subsequently demonstrated to be functional through real-world use in a Master-level lecture. After completion of this initial, platform-supported iteration of the simulation game, unstructured feedback was collected from the participants through feedback discussions. This feedback rounds off our first DSR iteration (published in [39]) and has been used to refine the extant objectives and the associated IT artifact. Since the feedback revealed considerable improvement potential, the platform was revised accordingly to be of better value for upcoming iterations (back to Step 3 in Figure 1). Based on the now revised platform another demonstration round was initiated, again including the now structured collection of feedback.

Over our iterations, we gathered considerable insights into how to improve the design of SGPs in the domain of e-competences. Among others, we aimed on gaining general insights into the usability of the platform interface, the closeness to reality, and the educational purpose. Hence, we decided to change the objectives that are addressed in the next DSR iteration and reported in this article. The core focus of our research is less on the IT artifact itself, but rather on deriving appropriate design principles that could guide similar research efforts [35] ("Level 2"-contribution [41]). For the derivation of the design principles, we use primarily the evaluation of the latest version of the platform (cf. Section 6.1) and compile the generated insights based on the guidelines outlined by [35]. As depicted in Figure 1, the demonstration and evaluation of the designed principles will not be part of this manuscript. 


\section{$4 \quad$ Platform Design}

We formalized and structured our goal of creating a configurable SGP for ecompetences by putting them into an Entity Relationship Model (ERM) to identify the necessary entities and their relationships. This is visualized in Figure 2.

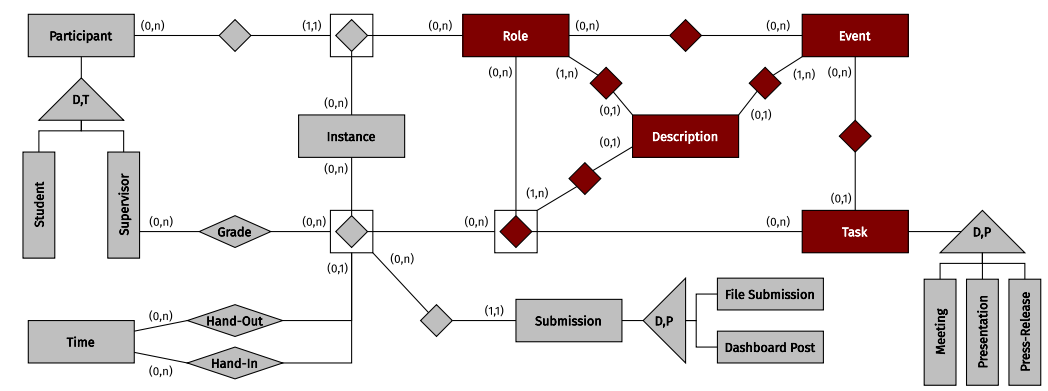

Figure 2. Data model of the "Game of Competences" [39]

In this figure, the red parts denote the components of competence-aimed simulation games as proposed by [12]. After breaking down the game, it consists of a set of roles, events, and tasks associated with the individual events - each typically accompanied by a description providing further details on each of these elements. As different roles have to fulfill different tasks throughout events, the role-specific tasks (RSTs) have been introduced (indicated through the re-interpreted relationship type) - again linked to a description providing further information. These elements suffice to map the desired simulation game to the virtual world. However, to carry out the simulation game the additional management "layer" is required-which in Figure 2 is depicted in gray. As indicated above, one of the major requirements is to host multiple parallel instances of each potential simulation game to cater to different courses throughout a given semester. Hence, both roles as well as RSTs are linked to participants, timeslots, and associated (graded) tasks only through instances (again using the reinterpreted relationship type). From an implementation perspective, the platform is realized as a traditional three-tier architecture separating client interfaces, business logic, and data storage [42]. To ensure stability, shareability, and ongoing of our work we consistently used established open-source technologies.

The current version of the Game of Competences has two different interfaces for its two primary user groups: participants (learners) and administrators (teachers), small parts of which are depicted in Figure 3 and Figure 4, respectively. In Figure 3, we see the so-called Dashboard, which is the landing page participants see after logging into the platform. In the screenshot, we see an exemplary post of the role The Hacker Group (the participants' names are intentionally omitted to enhance the immersion with the game) warning another partaking role of a security vulnerability in its tax systems. Aside from texts, participants can also attach images to support their message (we replaced an existing picture with the logo of the partaking student's university for copyright reasons). The dashboard serves as the communication center of the GoC, representing a chronological timeline of the ongoing events. Participants have further menu items that allow them to get an overview of pending assignments and the next 
tasks and events to be attended. By clicking on their role name in the top-right corner of the menu bar they can also review their role-related information.

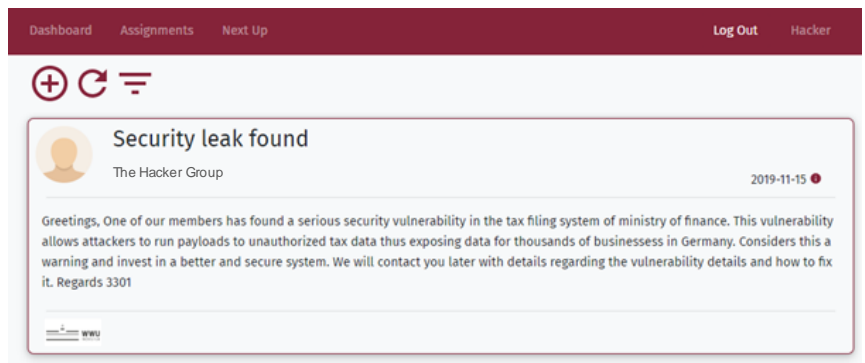

Figure 3. Participants' view of the GoC / The Dashboard [39]

As depicted in the menu bar at the top of Figure 4, game administrators also have access to the dashboard-simply as they can also interact with the participants there, but also need the access to assess and grade participants contributions there. The view almost fully corresponds to the view of the participants, with the distinction that the administrator can see and access all available posts-also those invisible to certain participants (parts of the game require communication between individual participants only). Aside from that, the menu bar contains two additional entries not available to the participants: The Session Management and the Game Management. At this point, the red and gray elements in Figure 2 become relevant again: The Game Management basically covers all elements depicted in red. Hence, a game in the terminology of the $\mathrm{GoC}$ is an abstract entity containing sets of roles, tasks, and events.

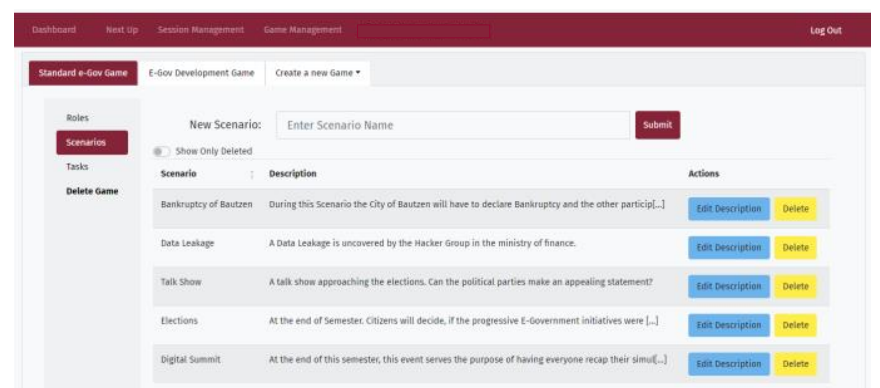

Figure 4. Administrators' view of the GoC / Game Management [39]

In the screenshot, you can see three tabs below the menu bar-one containing the simulation game proposed by [12] whereas the other one serves for development purposes. The third tab allows the creation of additional games. Within the tabs, the components of each game can be adjusted. To play a game with learners a so-called Session has to be instantiated (see the Instance-entity in Figure 2), which can then be administered through the Session Management. Through the Session Management the administrators can invite and manage the participants, schedule events, and assign tasks to the learners. Furthermore, in case the session is part of a graded teaching unit, the Session Management also offers functionalities to check timely submissions of tasks and to grade participants (GUI is structurally equivalent to Game Management). 


\section{$5 \quad$ Setting}

Last year the platform was first used to carry out the simulation game proposed by [12]. In that iteration, 25 international Master students enrolled in an e-government-oriented Master program participated in the simulation game. The simulation was embedded in a tech-oriented e-government lecture and the students were offered bonus points for continuous and constructive participation. That iteration has helped us to validate that having platform-support for carrying out such simulation games is both desirable and helpful [cf. 39]. Furthermore, we collected feedback on bugs and problems to improve the platform to a more smoothly working artifact.

Table 2. Overview of the student groups

\begin{tabular}{lccll} 
Semester & \# Students & Platform & \multicolumn{1}{c}{ Execution Mode } & \multicolumn{1}{c}{ Evaluation } \\
\hline $\begin{array}{l}\text { Summer } \\
\text { Term } \\
2018\end{array}$ & 17 & No & $\begin{array}{l}\text { Mainly offline; use of digital } \\
\text { means (Moodle, different } \\
\text { submission types, meetings) }\end{array}$ & $\begin{array}{l}\text { Feedback session; } \\
\text { individual } \\
\text { reflections; survey }\end{array}$ \\
\hline $\begin{array}{l}\text { Summer } \\
\text { Term }\end{array}$ & 25 & Yes & $\begin{array}{l}\text { Blended learning; platform } \\
\text { prototype; submissions to } \\
\text { platform, meetings. }\end{array}$ & $\begin{array}{l}\text { Feedback session; } \\
\text { unstructured bug } \\
\text { reports }\end{array}$ \\
\hline $\begin{array}{l}\text { Summer } \\
\text { Term }\end{array}$ & 27 & Yes & $\begin{array}{l}\text { Online; enhanced platform; } \\
\text { platform submissions, } \\
\text { communication via } \\
\text { platform, online meetings. }\end{array}$ & $\begin{array}{l}\text { Feedback session; } \\
\text { unstructured bug } \\
\text { reports; survey }\end{array}$ \\
\hline
\end{tabular}

In this paper, we focus on the second platform's iteration that was conducted in the summer term $2020^{1}$ with 27 international students of the same international Master's program as those of the first test iteration (cf. Table 2). The group consisted of students from different nationalities, having backgrounds primarily in social or political sciences but some also in more technical fields (e.g., computer science). While some studentsthrough work-experience - already had interactions with public administrations, the majority of the participants had no insights into the setup and interactions of public administrations (especially not the German ones which are the simulation case). The required background information was continuously delivered in the form of accompanying traditional lectures, providing background knowledge about egovernment in general as well as the German administrative system in particular. The further setup can be summarized as follows:

- to kick off the simulation game a one-hour introductory session was held, introducing the overall context, roles, and rules

- subsequently, each participant was assigned an individual role

- the role assignment was carried out at random

- role information was provided within the GoC platform and the initial invitation mail sent to the participants

- the platform itself only refers to the participants by their role names

- participants were encouraged to follow this pattern to enhance immersion

- to access the platforms the students could use whatever device they preferred

${ }^{1}$ Due to the COVID-19 pandemic, the originally blended approach was carried out digital-only on the platform, supported by individual Zoom sessions to ensure "personal" interaction. 
- the only restriction is that the platform could only be accessed through the university's VPN tunnel

- the game was subdivided into seven distinct events - each typically taking up two weeks of time where participants have to fulfill tasks

- typically, each participant has to fulfill up to two individual tasks (e.g., negotiations with another party, campaigning for elections) per event

- the average workload per week was about one hour strongly varying during the term

- the task schedule was not communicated to the students upfront-tasks were communicated through the game administrators or tasked participants

- to ensure that participants were notified about required actions, they received a mailnotification for each assigned task

- all in-game communication (incl. additional information from the game administrators or participant questions) the internal dashboard was used

At the end of the term, all participants were administered a link to a LimeSurvey, in which 17 out of 27 students participated. The survey was conducted anonymously and participants were given four weeks to fill in all questions. The survey took approx. 1015 minutes - with the option to pause and resume the survey. We split the survey into two larger parts. In the first part, we asked about the student's general perceptions regarding SGPs, notifications, and usability. The second part was about the instantiated platform the students used during the simulation game. In the survey, we presented statements (cf. Table 3 and Table 4) with the option to rate them according to a fivepoint Likert scale. In some questions, the participants had also the option to prioritize special features or to provide further thoughts or feedback.

Additionally, we carried out a feedback session with the participants. Throughout this session, they could provide us with all feedback that they could not fit into the structured survey administered earlier. As a further means, we implemented a so-called "Impersonate" feature into the platform, similar to the "Impersonate User" functionality known from the Drupal CMS. It allows administrators to view the platform "through the eyes" of the participants to track issues.

\section{Results}

\subsection{Evaluation}

Given the first overall positive evaluation of the Game of Competences as an instantiation in the summer term 2019, in the second evaluation, we additionally gained insights on how to design e-government SGPs in general.

Table 3. General perceptions on simulation game platforms

\begin{tabular}{lrrc} 
Question / Statement & + & $\mathrm{O}$ & - \\
\hline A digital platform is suitable for playing simulation games. & $75 \%$ & $12.5 \%$ & $12.5 \%$ \\
\hline $\begin{array}{l}\text { A simulation game platform is suitable for teaching e- } \\
\text { government settings. }\end{array}$ & $62.5 \%$ & $25 \%$ & $12.5 \%$ \\
\hline $\begin{array}{l}\text { Executing simulation games via digital platforms is superior } \\
\text { to less digital options (e.g., pen and paper, only by email). }\end{array}$ & $35.3 \%$ & $29.4 \%$ & $35.3 \%$ \\
\hline $\begin{array}{l}\text { Digital platforms contribute to make simulation games more } \\
\text { real. }\end{array}$ & $31.25 \%$ & $31.25 \%$ & $37.5 \%$ \\
\hline & + (completely) agree | O: indifferent |-: (completely) disagree
\end{tabular}


The presented evaluation results are based on the survey. Again, the majority of the participants rated the approach of using an SGP positive (cf. Table 3). Notably, this agreement decreases for e-government settings and disappears in comparison to other less digital options. This finding is supplemented by the preferences regarding task types, where the participants rated presentations and personal meetings as the most valuable means for a task. This indicates that a platform is not the one and unique solution for simulation games and, hence, has to be considered rather as a supporting tool for their execution.

Although, the reality aspect is important for a fruitful simulation game, a digital platform as such is not perceived as imitating real-world phenomena. Here, it turned out that notifications are seen as proper means to make a game more real (cf. Table 4). The initial purpose of notifications was simply to inform participants about tasks or events, which is unexceptionally rated as an important property. Beyond that, notifications also fulfill the function to convey a feeling of reality, e.g., a sense for pressure and urgency. Consequently, the evaluation revealed that notifications are more important for an SGP than anticipated. This finding influenced the formulation of design principle 3 .

Table 4. Perceptions on functions of simulation game platforms

\begin{tabular}{lrrr} 
Question / Statement & + & $\mathrm{O}$ & \multicolumn{1}{c}{-} \\
\hline Notifications are important for simulation game platforms. & $100 \%$ & $0 \%$ & $0 \%$ \\
\hline Notifications contribute to make a game setting more real. & $93.8 \%$ & $0 \%$ & $6.2 \%$ \\
\hline $\begin{array}{l}\text { For me, the notifications were important for playing the } \\
\text { simulation game. }\end{array}$ & $93.3 \%$ & $6.6 \%$ & $0 \%$ \\
\hline $\begin{array}{l}\text { I would like to receive notifications for every action or event } \\
\text { that affects my role. }\end{array}$ & $86.7 \%$ & $13.3 \%$ & $0 \%$ \\
\hline $\begin{array}{l}\text { I would have appreciated additional help functions on the } \\
\text { platform. }\end{array}$ & $60 \%$ & $20 \%$ & $20 \%$ \\
\hline & + (completely) agree $\mid$ O: indifferent $\mid-$ (completely) disagree
\end{tabular}

A further aspect to keep track of when developing SGPs are help functions. Even though exhaustive documentation was provided before the game started which was read by all players beforehand except of one, the evaluation revealed additional relevance of help functions. The majority of players expects additional help functions. Specifically, FAQs $(75 \%)$ and tooltips $(45 \%)$ were rated as the most compelling alternatives, whereas no one rated for personal tutorials $(0 \%)$. This finding especially influenced the formulation of design principle 5 .

In addition, the survey results gave meaningful insights for the design principles regarding communication, workload transparency, and training of competences. The participants argued for an expansion of the current communication channel since the platform should "allow actual interaction between characters, (...) to form groups (...) and share stuff in between". "Discussion threads or chat/email function" were also mentioned. Other participants pointed out that an overview "of the work done and events that happened until the present moment" and a "scoring system which assigns points for every task [immediately] " would be beneficial to reach more transparency about the workload. Lastly, the evaluation showed, on the one hand, that the participants had a good understanding of the targeted competences of the game and, on the other hand, that this aim was not met for all these target competences. 


\subsection{Design Principles}

Based on the evaluation results and the learnings gathered throughout the platform development and implementation, we set forth with shaping and formulating the design principles. Finally, the iterative development process revealed seven design principles for the successful implementation and application of e-government simulation games:

1. Build the platform scalable to different numbers of game roles, events, and tasks in order to ensure applicability to varying group sizes and equal shares of workload for users.

This principle aims at the uncomplicated scalability of the platform. Learner groups vary in their size and game settings vary in their scope implicating an adjustment of the task distribution. For instance, with a rising number of game roles, the interaction possibilities among these roles increase disproportionally. Thus, adherence to the first principle ensures that varying group sizes are possible and do not affect the individual workload or competences to be trained. Here, scalability considers two distinct perspectives. First, the ordinary, usual purpose to cope with varying group size. Second, in a simulation game, scaling involves the further implication of keeping the workload on the same level since the game dynamics need also to scale up. Other platforms that only provide content or the possibility for interactions-without a dedicated workload for users - only need to adhere to the first aspect. So, the principle is primarily designed for learners' convenience as it allows a consistent game execution irrespective of the number of game roles, i.e., participants.

2. Build the platform configurable to different numbers of game roles, events, and tasks in order to ensure quick game customization for teachers.

This principle aims at the adaptability of the platform to different game scenarios. The structure, scope, complexity, and duration of simulation games can be different according to the application setting. For instance, a simulation game used to train public officials might have fewer events and tasks compared to using it as a supporting supplement to an e-government lecture, in order to account for time and other resourcerelated constraints in public administrations. Furthermore, the application on different federal levels will require different setups to accommodate the different tasks and responsibilities in the different administrative layers. In contrast to configurability in its usual fashion, an e-government SGP needs technical and content-related configurability. The platform needs to adapt to a plethora of different game scenarios (content-related) but also to various application scenarios (technical), in which teachers/learners might have different administrative/access rights or the default communication channels/notifications need adaptations. Thus, adherence to the second principle ensures that teachers can customize the number of game roles, events, and tasks according to the needs of the learner group and also to different game scenarios. The principle ensures to add or delete roles, events, and tasks as needed.

3. Build the platform with real-time notifications and interaction channels in order to convey a feeling of reality for the users.

This principle aims at the actual simulation of real-world phenomena. Beyond the game scenario as such, especially interaction mechanisms contribute to making simulation games more realistic. For instance, sudden events like data leakages or 
bankruptcies require immediate responses and prior arrangements among affected parties - in the real and in the fictitious setting. Thus, adherence to the third guideline ensures that the game becomes a constant companion while playing it. On the one hand, participants are faced with unforeseen happenings and need to react appropriately. On the other hand, participants also receive simple information about the happenings or actions of the other players, which keep them permanently updated.

4. Build the platform with a distinct communication channel for learner-teacher interaction in order to install channels for providing confidential feedback.

This principle aims at integrating the organizational context of the game into the platform. The execution of simulation games also comes along with conventional learners' problems or uncertainties. For instance, during the game, questions of understanding arise or participants provide and receive feedback on tasks. Thus, the adherence to the fourth principle ensures the embedding of real-world supervision into the platform and that no switching to other media is necessary. This requirement is of increased importance in cases of non-blended setups.

5. Build the platform with different help functions in order to ensure that users are able to use every available functionality.

This principle aims at keeping the flow of play by mitigating problems while using the platform. An SGP contains many features for uploads, posts, overviews, feedbacks, etc. For instance, a simple dashboard post may contain several options each for addressee selection, attachments, text formatting, or figures, which might be overwhelming for certain user groups. Thus, the adherence to the fifth principle ensures that in case of issues with platform functions, first, no interruption of the current game action is needed and, second, teachers and learners find immediate support when making changes to the game.

6. Build the platform with a role's workload overview in order to inform participants on remaining time for submission and lower the uncertainty level regarding game organization given that providing this information does not affect the game.

This principle aims at providing the participants with reasonable transparency regarding game execution. When playing a simulation game, the participants' time constraints regarding work, studies, or private affairs must be considered. Thus, adherence to the sixth principle ensures that the participants always have a general overview of upcoming tasks when entering the platform. Furthermore, such an overview helps game administrators to fairly distribute tasks and events among participants even in larger and complex setups. This reduces potential time conflicts and needs to be balanced with principle 3 .

7. Build the platform with competence-specific task templates in order to use appropriate task types that are dedicated to train certain competences.

This principle aims at a targeted training of e-government competences. The wide range of different task types can be structured according to their contribution to building up certain competences. For instance, to gain political-administrative competences it is recommended to use tasks that yield background knowledge and domain understanding of the public sector. Thus, adherence to the seventh principle allows training for certain competence profiles. 


\section{Discussion \& Conclusion}

The evaluation goes beyond a classical artifact evaluation and revealed important additional aspects to be considered in e-government SGPs. Together with the learnings gained in the development process, the evaluation strongly contributed to shaping and refining the design principles. Based on the well-documented research process, the developed design principles constitute a transfer channel from how to educate egovernment competence to its implementation in SGPs.

However, the design principles strongly differ in their domain orientation. For instance, design principles 3 and 7 take up specifics of the public sector, e.g. required interaction in a complex mesh of stakeholders and a focus on educating e-government competences. In contrast, principles 1 and 2 aiming at scalability, equal workload, and quick customization, may have to be considered also in other application domains. However, both principles ensure the flexible application into different curricula or the consideration of different educational levels of students. Although these two principles are similarly proposed by [23], up to now, our findings cannot confirm a transferability to other domains since targeted competences may be different from those of public administration. Recently, the simulation game has been adapted as an employee version, i.e., as a variant of the game that can be used to train public sector official's ecompetences [43]. Normally, public servants can only participate in training programs to a limited extent. As such not only the content of the game needs to be modularized but also the gaming platform needs to adequately address the requirements of high scalability and workload transparency.

Regarding the evaluation of both the simulation game and the according platform indicate that neither a complete analogue nor a completely digital setup are appropriate means to convey e-competences. Rather, the students' evaluations indicate a preference for blended learning, i.e., the combination of analogue and digital formats. The SGP proposed in this article is designed as a solution for this requirement as it is conceptualized as a supportive instrument for the execution of the game rather than as the central element of the game.

Even though digitalization is not new, many public authorities and administrations are only recently catching up and identified lacking digital competences as a major hindrance $[13,44]$. To catch up on a competent workforce, new study courses are created by individual administrations [45], with Qualifica Digitalis an overall qualification requirement assessment was started [44], and the IT planning council in Germany is establishing an online qualification program [46]. There, simulation games are explicitly mentioned as one means to avoid merely conveying theory but giving students practical experiences, which is crucial for these practice-oriented educational programs [44]. The usability of the platform was not explicitly considered during our evaluation and the derivation of our design principles. While usability is known to be a central feature of IT artifacts to ensure their adoption, there is already a plethora of usability related research available that addresses usability in general [47] and even for e-learning platforms [48]. To avoid unnecessary lengths and duplicated effort, corresponding design requirements were omitted. 
The goal of our research was two-fold. First, we developed an SGP tailored to the public domain based on the simulation game proposed by [12]. The platform was iteratively designed and tested in a study group of international students. Second, we used the platform and the associated development and evaluation processes as vehicles to derive seven design principles for e-government SGPs following an extensive and well-documented research process. The design principles are a step towards theoretical guidance for the implementation of SGPs for e-government. These outcomes entail implications for research and practice. Our research extends the research on SGPs to the e-government area. Now, the research community can further test the design principles and investigate their generalizability and fit other domains. In addition, practitioners may use our results as a blueprint and guideline to the development of SGPs, thus, facilitating the diffusion and use of digitally supported simulation games for public sector education.

Limitations of the research comprise the sample of students. Although, the students who participated in (both) evaluations were very engaged and a critical audience, these groups are not a representative sample. Of course, they had a suitable lens for the public sector but, for example, public officials might have different preferences. Also, the design principles are not applicable to every kind of simulation game as they focus on games with interactions. All in all, our research is a contribution to the theoretical embedding of SGP development in the public sector domain.

\section{Acknowledgements}

The platform was developed for the ERASMUS Mundus Master of Science in Public Sector Innovation and eGovernance (PIONEER) at the University of Münster and was evaluated with the students. We express our thanks for their valuable contributions.

\section{References}

1. Persson, A., Goldkuhl, G.: Government Value Paradigms - Bureaucracy, New Public Management, and E-Government. Commun. Assoc. Inf. Syst. 27, 45-62 (2010).

2. Wimmer, M.A.: Integrated Service Modelling for Online One-stop Government. Electron. Mark. 12, 149-156 (2002).

3. Scholta, H., Mertens, W., Kowalkiewicz, M., Becker, J.: From one-stop shop to no-stop shop: An e-government stage model. Gov. Inf. Q. 36, 11-26 (2019).

4. Janssen, M., Charalabidis, Y., Zuiderwijk, A.: Benefits, Adoption Barriers and Myths of Open Data and Open Government. Inf. Syst. Manag. 29, 258-268 (2012).

5. Ogonek, N., Hofmann, S.: Governments' Need for Digitization Skills: Understanding and Shaping Vocational Training in the Public Sector. Int. J. Public Adm. Digit. Age. 5, 61-75 (2018).

6. Müller, S.D., Skau, S.A.: Success factors influencing implementation of e-government at different stages of maturity: a literature review. Int. J. Electron. Gov. 7, 136 (2015).

7. Stefanovic, D., Marjanovic, U., Delić, M., Culibrk, D., Lalic, B.: Assessing the success of e-government systems: An employee perspective. Inf. Manag. 53, 717-726 (2016).

8. Freitas, S. De, Liarokapis, F.: Serious Games and Edutainment Applications. In: Ma, M., Oikonomou, A., and Jain, L.C. (eds.) Serious Games and Edutainment Applications. pp. 923. Springer-Verlag, London (2011).

9. Sanina, A., Kutergina, E., Balashov, A.: The Co-Creative approach to digital simulation games in social science education. Comput. Educ. 149, (2020). 
10. Löffler, A., Levkovskyi, B., Prifti, L., Kienegger, H.: Teaching the Digital Transformation of Business Processes : Design of a Simulation Game for Information Systems Education. 14th Int. Conf. Wirtschaftsinformatik. 315-329 (2019).

11. Klievink, B., Janssen, M.: Simulation games for collaborative development in eGovernment. In: Proceedings of the 43rd Hawaii International Conference on System Sciences (HICSS). pp. 1-9 (2010).

12. Ogonek, N., Distel, B., Becker, J.: Let's Play ... eGovernment! A Simulation Game for Competence Development among Public Administration Students. Proc. 52nd Hawaii Int. Conf. Syst. Sci. 3087-3096 (2019).

13. Ogonek, N.: Imparting Electronic Government Competences, (2019).

14. Heeks, R.: Most eGovernment-for-Development Projects Fail: How Can Risks be Reduced?, Manchester, UK (2003).

15. Hunnius, S., Paulowitsch, B., Schuppan, T.: Does E-government education meet competency requirements? An analysis of the German university system from international perspective. In: Proceedings of the Annual Hawaii International Conference on System Sciences. pp. 2116-2123 (2015).

16. European Commission: eGovernment Benchmark 2016. A turning point for eGovernment development in Europe? , Luxembourg (2016).

17. Mergel, I.: Kompetenzen für die digitale Transformation der Verwaltung. Innov. Verwaltung. 4, 34-36 (2020).

18. Distel, B., Ogonek, N., Becker, J.: eGovernment Competences Revisited - A Literature Review on Necessary Competences in a Digitalized Public Sector. In: 14th International Conference on Wirtschaftsinformatik. pp. 286-300. , Siegen, Germany (2019).

19. Lean, J., Moizer, J., Towler, M., Abbey, C.: Simulations and games: Use and barriers in higher education. Act. Learn. High. Educ. 7, 227-242 (2006).

20. Mayer, I., Veeneman, W.: Games in a world of infrastructures simulation-games for research, learning and intervention. , Delft (2002).

21. Mayer, I., Bekebrede, G., Warmelink, H., Zhou, Q.: A Brief Methodology for Researching and Evaluating Serious Games and Game-Based Learning. In: Connolly, T.M., Hainey, T., Boyle, E., Baxter, G., and Moreno-Ger, P. (eds.) Psychology, Pedagogy, and Assessment in Serious Games. pp. 357-393. IG (2013).

22. Deterding, S., Dixon, D., Khaled, R., Nacke, L.: From Game Design Elements to Gamefulness: Defining "Gamification.” In: Proceedings of the 15th International Academic MindTrek Conference: Envisioning Future Media Environments. pp. 9-15 (2011).

23. El-Masri, M., Tarhini, A.: A Design Science Approach to Gamify Education: From Games to Platforms. In: 23rd European Conference on Information Systems (ECIS). pp. 1-10. , Münster, Germany (2015).

24. Blohm, I., Leimeister, J.M.: Gamification: Design of IT-based enhancing services for motivational support and behavioral change. Bus. Inf. Syst. Eng. 5, 275-278 (2013).

25. Hamari, J., Koivisto, J., Sarsa, H.: Does gamification work? - A literature review of empirical studies on gamification. Proc. Annu. Hawaii Int. Conf. Syst. Sci. 3025-3034 (2014).

26. Connolly, T.M., Boyle, E.A., MacArthur, E., Hainey, T., Boyle, J.M.: A systematic literature review of empirical evidence on computer games and serious games. Comput. Educ. 59, 661-686 (2012).

27. Liu, C.C., Cheng, Y.B., Huang, C.W.: The effect of simulation games on the learning of computational problem solving. Comput. Educ. 57, 1907-1918 (2011). 
28. Cook, N.F., McAloon, T., O’Neill, P., Beggs, R.: Impact of a web based interactive simulation game (PULSE) on nursing students' experience and performance in life support training - A pilot study. Nurse Educ. Today. 32, 714-720 (2012).

29. Chang, Y.C., Chen, W.C., Yang, Y.N., Chao, H.C.: A flexible web-based simulation game for production and logistics management courses. Simul. Model. Pract. Theory. 17, 12411253 (2009).

30. Herranz, E., Colomo-Palacios, R., Seco, A. de A.: Gamiware: A gamification platform for software process improvement. In: Communications in Computer and Information Science (2015).

31. Simões, J., Redondo, R.D., Vilas, A.F.: A social gamification framework for a K-6 learning platform. Comput. Human Behav. 29, 345-353 (2013).

32. Pasin, F., Giroux, H.: The impact of a simulation game on operations management education. Comput. Educ. 57, 1240-1254 (2011).

33. Grabka, T.: Referenzmodelle für Planspielplattformen - Ein fachkonzeptioneller Ansatz zur Senkung der Konstruktions- und Nutzungskosten computergestützter Planspiele, (2006).

34. Gregor, S., Hevner, A.R.: Positioning and Presenting Design Science. MIS Q. (2013).

35. Chandra, L., Seidel, S., Gregor, S.: Prescriptive knowledge in IS research: Conceptualizing design principles in terms of materiality, action, and boundary conditions. Proc. Annu. Hawaii Int. Conf. Syst. Sci. 2015-March, 4039-4048 (2015).

36. Hevner, A.R., March, S.T., Park, J., Ram, S.: Design Science in Information Systems Research. MIS Q. 28, 75-105 (2004).

37. Peffers, K., Tuunanen, T., Rothenberger, M.A., Chatterjee, S.: A Design Science Research Methodology for Information Systems Research. J. Manag. Inf. Syst. 24, 45-77 (2008).

38. Peffers, K., Tuunanen, T., Niehaves, B.: Design science research genres: introduction to the special issue on exemplars and criteria for applicable design science research. Eur. J. Inf. Syst. 27, 129-139 (2018).

39. Becker, J., Niemann, M., Halsbenning, S.: (Playing) Government beyond Pen \& Paper: Conceptualization, Implementation, and Outlook. In: Proceedings of the 15th International Conference on Wirtschaftsinformatik. pp. 493-498 (2020).

40. Iivari, J.: A Paradigmatic Analysis of Information Systems As a Design Science A Paradigmatic Analysis of Information Systems As a Design Science. Scandanavian J. Inf. Syst. 19, 39-64 (2007).

41. Gregor, S., Hevner, A.R.: Positioning and Presenting Design Science Research for Maximum Impact. MIS Q. 37, 337-355 (2013).

42. Eckerson, W.W.: Three Tier Client/Server Architecture: Achieving Scalability, Performance, and Efficiency in Client Server Applications. Open Inf. Syst. 10, (1995).

43. Ogonek, N., Distel, B., Hofmann, S.: Kompetenzvermittlung im öffentlichen Sektor neu gedacht. (2020).

44. Schmeling, J., Bruns, L.: Kompetenzen, Perspektiven und Lernmethoden im Digitalisierten Öffentlichen Sektor., Berlin, Germany (2020).

45. land.nrw: Neuer Studiengang zum Verwaltungsinformatiker.

46. IT-Planungsrat: Entscheidung 2019/62 - Bildungs- und Weiterbildungsplattform EGovernment.

47. Nielsen, J.: Usability Inspection Methods. In: Conference companion on Human factors in computing systems - CHI '94. pp. 413-414., Boston, Massachusettes (1994).

48. Harrati, N., Bouchrika, I., Tari, A., Ladjailia, A.: Exploring user satisfaction for e-learning systems via usage-based metrics and system usability scale analysis. Comput. Human Behav. 61, 463-471 (2016). 